\title{
Amador e profissional no teatro brasileiro: motivações ideológicas e aspectos econômicos na identidade de grupos teatrais do início do século XXI
}

Amateur and professional in Brazilian theater:

ideological motivations and economic aspects

in the identity of XXI century theater groups

Elderson Melo de Melo ${ }^{1}$

Mariana Baruco Machado Andraus²

Resumo

Este texto traz uma reflexão acerca do sentido atribuído historicamente aos termos amador e profissional no teatro produzido no Brasil. Aborda o conceito de teatro amador, buscando sua aplicação em vários momentos históricos e sua caracterização em distintas correntes teatrais consideradas amadoras, especialmente aquelas que caracterizam as produções do século XX. Pretende-se, por meio desta análise, entender o lugar dos termos amador e profissional no cenário teatral brasileiro da atualidade.

Palavras-chave: História do teatro. Teatro brasileiro.

Teatro amador.

\section{Abstract}

This paper presents a reflection about the historically assigned meaning of the terms amateur and professional within the theater produced in Brazil. It discusses the concept of "amateur theater", looking for definitions throughout several amateur theater streams, particularly those that are characteristic of the twentieth century. We intend, through this analysis, to understand the current circumstances of the usage of the terms amateur and professional in the theatrical scenario in Brazil.

Keywords: Theater history. Brazilian theater.

Amateur theater.

1.

Docente do Curso Superior de Teatro da Pontifícia Universidade Católica do Paraná. Doutorando em Educação pela Universidade de São Paulo (USP). Email: eldersonmelo@gmail.com

2.

Coordenadora do Programa de Pós-Graduação em Artes da Cena da Universidade Estadual de Campinas (Unicamp). Docente do Curso de Graduação em Dança (Departamento de Artes Corporais, Unicamp). Doutorado em Artes da Cena (Unicamp, bolsista Capes), PósDoutorado em Educação (PUCCampinas, bolsista Capes). 
Este artigo traz uma reflexão acerca do sentido atribuído historicamente aos termos amador e profissional no teatro produzido no Brasil. Teatro amador, neste trabalho, é entendido como aquele produzido por atores que realizam suas iniciativas por prazer, sem finalidades comerciais, e não pelo mérito ou qualificação do trabalho. Pelo contrário, parte-se do pressuposto de que existem produções amadoras qualificadas e que, inclusive, influenciam e levam à criação de vertentes dentro deste campo de atuação e pesquisa.

No Brasil, a produção de arte amadora esteve presente nas diversas linguagens das artes desde o período colonial, com obras de alta qualidade sendo elaboradas continuamente. O teatro amador, dentre os modos de produção das artes da cena, é, sem dúvida, um forte integrante da arte teatral brasileira, aparecendo na historiografia especializada sobre o assunto como uma manifestação artística que recorre desde os primórdios da produção dessa linguagem. Discutir sua existência, história, características e as razões pelas quais muitos agrupamentos sociais se dedicam ao teatro de forma amadora é fundamental para o entendimento da própria história do teatro produzido no Brasil.

Tendo em vista esta premissa formulamos, como ponto de partida, a seguinte questão: "O que significa, afinal, ser amador ou profissional na arte do teatro no início do século XXI?’. Para respondê-la, é necessário pensar em como a prática amadora vinculou-se historicamente ao teatro produzido no Brasil. Em seguida, discutiremos sobre quais sentidos são atribuídos às palavras amador e profissional por grupos de teatro que participaram da pesquisa de Melo (2010), desenvolvida no Acre, sobre esta temática, para, enfim, tecermos nossas considerações sobre a utilização e os significados desses termos no teatro brasileiro da atualidade.

\section{O amador no teatro brasileiro}

Durante a colonização brasileira, uma das formas teatrais que possuía características amadoras eram os entremezes ${ }^{3}$, realizados já durante as navegações por marujos e feitos por puro entretenimento; e também os autos jesuítas, no período de colonização, que tinham por objetivo principal o ensinamento de preceitos cristãos. Da mesma forma, os espetáculos cívicos e religiosos que foram apresentados durante os séculos XVI e XVII serviam apenas como forma de comunicação e celebração, sendo realizados por pessoas não dedicadas ao teatro, que faziam representações sem fins
3.

Entremezes são composições dramáticas burlescas, de caráter breve, que servem de entreato em uma peça teatral. 
lucrativos e com apresentações realizadas para determinado evento em locais e períodos determinados, sem uma continuidade de trabalho.

Até o final do século XIX, pode-se dizer que as produções nacionais foram feitas de maneira predominantemente amadora, no sentido de que as representações realizavam-se em manifestações esporádicas, de cunho muitas vezes informal, sem finalidades comerciais, e que, nessa época, não chegavam a mobilizar um discurso teatral mais consistente. Eram poucos os agrupamentos sistematicamente organizados em forma comercial. Entre eles, podemos citar montagens de dramaturgos brasileiros como Gonçalves Magalhães e Martins Pena realizadas em teatros criados pela corte portuguesa. Durante esse período, alguns grupos organizados de forma amadora também podem ser citados, como os de algumas associações de amadores criadas em Curitiba-PR, em 1887, em Vitória-ES, e em outras localidades do território imperial brasileiro (Faria, Guinsburg, Lima, 2006).

Durante o início do século $\mathrm{XX}$, em um período em que começaram a ser organizados de forma mais sistemática grupos teatrais no Brasil, tanto amadores quanto profissionais, o teatro brasileiro restringiu-se em termos de diversidade de seus gêneros artísticos. Até os anos 1940, predominou como produção teatral feita por grupos já profissionais (que produziam comercialmente) quase exclusivamente a comédia de costumes. As poucas mudanças produzidas em termos de linguagem no cenário teatral eram realizadas, segundo alguns autores, por grupos de amadores. Sobre o assunto, Ana Bernstein afirma:

As escassas tentativas de representação de gêneros "sérios", como o drama, deviam-se aos grupos amadores, provenientes de clubes, grêmios, círculos dramáticos e associações de teatro (...). Como não havia escolas, a renovação dos quadros profissionais devia-se, quase sempre, à incorporação de elementos oriundos do teatro amador. Começa a se afirmar, com estes grupos, uma nova mentalidade teatral (Bernstein, 2005, p. 44).

Entre os anos 1900 e 1920, Renata Palottini (1974) diz que ocorreram espetáculos significativos e publicações de grupos que se autodenominavam amadores ${ }^{4}$. Segundo a autora, havia "(...) dezenas de grupos de amadores com atividades regulares e comprovadas. Essas atividades eram de tal ordem que, em 1908, vinha à luz um quinzenário, 0 amador dramático, dedicado exclusivamente à classe" (p. 76).

No que se refere ao teatro em São Paulo, durante a Primeira República, Vargas e Magaldi argumentam que:
4.

Para maiores detalhes, ver FARIA, João Roberto; GUINSBURG, Jacob; LIMA, Mariângela Alves de, op. cit. 
[...] desenvolveu-se um teatro com características próprias, feito por italianos e dirigido principalmente à coletividade italiana. Portadores das mais variadas idéias (...), enérgicos e lutadores em grande parte libertários, foram os imigrantes - segundo Franco Cenni, em seu livro Italianos no Brasil - que conseguiram romper as "invisíveis fronteiras que tolhiam o passo a uma renovação" (Vargas e Magaldi, 2000, p. 32).

No Rio de Janeiro, o Teatro de Brinquedo foi criado em 1927 por Eugênia e Álvaro Moreyra. O grupo era composto principalmente por amadores. A primeira peça apresentada foi a comédia Adão, Eva e outros membros da família, de autoria do próprio Álvaro Moreyra, que criticava as incoerências da sociedade capitalista com a história de um ladrão e um mendigo na qual o primeiro virava capitalista, e o segundo, dono de jornal. Vargas e Magaldi (2000) relatam a importância do Teatro de Brinquedo para sua época: "O Teatro de Brinquedo é saudado como uma bela tentativa de amadores, que já é uma realidade vitoriosa, capaz de influir seriamente na evolução do nosso meio cênico" (p. 113).

Em 1938, Pascoal Carlos Magno (1906-1980) criou, também no Rio de Janeiro, o Teatro do Estudante. Em 1948, o italiano Franco Zampari (1898-1966) fundou o Teatro Brasileiro de Comédia (TBC), em São Paulo - criado, segundo Palottini (1974), a partir da junção de dois grupos amadores: o Grupo de Teatro Experimental e o Grupo de Teatro Universitário. Em 1938 foi criado o grupo Os Comediantes, companhia teatral amadora carioca que, segundo a Enciclopédia Itaú Cultural,

[...] consolida o movimento de teatro amador que desde o final dos anos 1920 procura transformar o panorama teatral no Rio de Janeiro, onde predominam montagens comerciais de comédias de costumes. Com a encenação de Vestido de Noiva, de Nelson Rodrigues, sob a direção de Ziembinski, Os Comediantes inauguram a modernidade no teatro brasileiro (Enciclopédia Itaú Cultural, 2011).

Foi assim que, ao longo dos anos 1930 e 1940, os empreendimentos autointitulados amadores trouxeram um movimento amador organizado para o teatro brasileiro. Esses grupos espalhavam-se por todo o Brasil, realizando produções teatrais cada vez mais elaboradas e fortalecendo a linguagem teatral no país, produzindo festivais e organizando grupos que se denominavam amadores. Sua perspectiva vinculava-se muito mais a uma questão ideológica do que a uma questão técnica, muito embora fossem os precursores de linguagens e de renovações significativas na cena teatral do país, conforme visto.

Durante o final da década de 1940 até a década de 1970, 
período conhecido como modernização do teatro brasileiro, marcado por ações de renovação do meio cênico mediante o fortalecimento de companhias comandadas por produtores e encenadores, o teatro amador continuou com grande visibilidade e atuação, sendo valorizado ideologicamente como importante para a produção teatral no Brasil.

Nesse caminho é que surgiu, em 1974, uma das maiores e mais significativas instituições do movimento de teatro do Brasil: a Federação Nacional de Teatro Amador (Fenata), que viria a reunir afiliadas por todo o Brasil. Essa instituição teve como propósito agrupar os muitos grupos autointitulados amadores que se encontravam espalhados pelo país. Kühner (1987) enumera os Princípios e Diretrizes da Fenata (Art. 14), quando de sua criação, nos quais se percebe a necessidade de afirmação do movimento amador e do sentido democrático do teatro. Transcrevemos aqui os princípios pertinentes à nossa discussão: $i$. a superação de uma marginalidade que a maior parte das vezes enfraquece, torna efêmero ou mesmo anula o trabalho dos grupos; ii. o estímulo à criação de novos grupos; e iii. a uniformização nacional do tratamento dispensado pelos órgãos oficiais aos grupos amadores, tratamento este que não pode nem deve comportar as mesmas exigências legais feitas às companhias profissionais.

Um ano mais tarde, em 1975, a Fenata passou a se chamar Confederação Nacional de Teatro Amador (Confenata), que foi responsável, entre outras coisas, pela promoção do Festival Brasileiro de Teatro Amador (FBTA), do Festival Brasileiro de Teatro Amador Infantil (FBTAI) e de mostras regionais de teatro.

Esses grupos expressivamente atuantes no teatro produzido no Brasil do final do século XX garantiram a consolidação de um discurso organizado sobre "teatro de grupo", no sentido ideológico do termo. Valorizavam predominantemente a criação de grupos teatrais que incluíssem militância e engajamento de seus integrantes. No II Congresso de Teatro Amador, no ano de 1981, a Confenata publicou a seguinte nota:

\footnotetext{
O Teatro Amador é, sem dúvida alguma, o melhor veículo para que se atinja a democratização do teatro. É ele que permite, e tem permitido, que cada vez mais pessoas possam não só ter acesso a espetáculos teatrais como participar dessa manifestação que hoje já se espalha por todo o País. O Teatro Amador, hoje, está presente em todos os estados e territórios do País (Kühner, 1987, p. 170).
}

Em temário proposto em setembro de 1982 para o III Congresso de Teatro Amador, realizado em Aracaju, de 20 a 23 de janeiro de 1983, a Confenata propôs como tema de discussão "A organização dos amadores", incluindo como pauta: 
2.1 - O grupo amador

Considerando que:

a) existe uma diferença fundamental entre os grupos amadores e os elencos formados circunstancialmente em função de eventuais montagens teatrais e que a estrutura do grupo de teatro amador tem uma série de outros requisitos além da simples constituição de elenco;

b) podemos caracterizar os atores, quanto à sua presença nos grupos, como engajados nos mesmos ou como "flutuantes", isto é, os que transitam de uma para outra montagem;

c) os grupos estão sempre necessitando da presença de elementos que possam contribuir para os seu crescimento, mesmo que não sejam integrantes efetivos;

\section{CONCLUIMOS QUE:}

a) a presença dos artistas amadores "flutuantes" - prestadores de serviços em determinadas produções - no seio do movimento é prejudicial na medida em que esses artistas não se integram à discussão e à continuidade do fazer teatral dos grupos, não se engajando portanto a uma luta maior pela autonomia e livre expressão do teatro amador;

b) $[\ldots]$

c) $[\ldots$.

d) a utilização do nome amador e sua condição jurídica para a exploração comercial e o uso de benefícios específicos dos amadores em proveito próprio, individual, são práticas equivocadas, pois desagregam o movimento teatral amador e esvaziam as lutas dos trabalhadores profissionais das artes cênicas. Esse fato também tem impedido a participação e o avanços dos trabalhos executados por grupos ligados ou provenientes de movimentos populares, os quais não têm a preocupação capitalista ou comercial com a sua prática teatral. Por isso, essa prática oportunista deve ser repudiada e denunciada aos órgãos do movimento teatral brasileiro (Kühner, 1987, p. 218).

Percebe-se que, já no período de realização desse evento, houve uma plena e sofisticada organização do Movimento de Amadores. Nos anos de 1982-1983, a noção de que o teatro deve-se vincular ideologicamente (militância, engajamento) era aceita como importante para os amadores. Isso os diferenciaria de agrupamentos cujo propósito maior é o lucro, ou seja, a finalidade comercial, e que, portanto, não teriam por fundamentos a democratização e a acessibilidade do fazer teatral. Tais princípios eram levados tão a sério que isso fazia com que os dirigentes repudiassem formas de vínculos com caráter esporádico, feitas para produções específicas, desvinculada de uma causa social. Segundo essa lógica, essas qualidades enfraqueceriam o movimento amador e levariam à desestruturação das lutas pela autonomia e consolidação do movimento.

No final da década de 1990 e início dos anos 2000, no entanto, a atuação da Confenata e das suas federações filiadas foi se enfraquecendo. Oficialmente, a maioria das instituições de caráter 
semelhante ao da Confenata, hoje em dia, foi extinta, possuindo inclusive uma trajetória histórica muito pouco estudada. No mesmo caminho, a expressão "teatro amador" assumiu, pouco a pouco, um lugar de desqualificação no cenário teatral brasileiro. É comum ouvir afirmações de que o termo amador encontra-se em desuso, não devendo mais ser utilizado para identificação de grupos. Isso foi verificado por Melo (2010) em seus estudos sobre o teatro de grupo no Acre, como veremos a seguir.

O que levou, afinal, a essa mudança na concepção e entendimento do termo amador no teatro? Por que a expressão assumiu hoje um valor negativo? Isto se deve, a nosso ver, a um desgaste da própria função da ideologia no teatro, o que levou a uma visão de que o termo amador, vinculado nos últimos anos do século XX à premissa de militância e engajamento, estaria ligado à ideia de despreparo, atribuindo-se valor à expressão "teatro profissional" por sua ligação direta com a qualificação técnica.

Usos dos termos amador e profissional no início do século XXI

Durante toda a existência das associações amadoras, organizadas no século XX, especialmente da Confenata, o teatro brasileiro equilibrou a valorização das expressões amador e profissional. Passado algum tempo desde a época em que se produzia teatro por motivações ideológicas, recai sobre o termo amador um caráter negativo. Isso significa uma inversão nas concepções de produção teatral no Brasil, demostrando o esfacelamento dos modelos antes levantados por agrupamentos teatrais como os que se vinculavam à Confenata.

No trabalho desenvolvido por Melo (2010), que objetivou entender as características estruturais dos grupos de teatro atuantes no estado do Acre, em 2010, percebeu-se que os entrevistados tenderam a se designar como profissionais quando questionados: "Como seu grupo se considera, amador ou profissional, e por quê?"; isso em um estado que tem uma forte tradição de teatro amador no sentido ideológico, com uma participação ainda efetiva da Federação de Teatro Amador no Acre (FETAC), cuja origem remonta ao trabalho realizado no passado pelas Confenatas. Dos entrevistados, 70\% responderam que o seu trabalho era profissional - sendo que, na capital, onde circula um maior discurso e prática de criação teatral, esse número foi maior, chegando a mais de $80 \%$ dos grupos.

A análise das diversas respostas levou Melo a interpretar que houve uma necessidade, por parte dos grupos, de se autodesvincularem da expressão "teatro amador". O Quadro 1 
mostra as respostas selecionadas pelos 17 grupos que responderam ao questionário (identificando-se como profissionais ou amadores) e as justificativas apresentadas pelos grupos para suas respectivas respostas. Observa-se que a maioria dos entrevistados se autodenominou profissional, justificando a resposta com motivos relacionados à valorização das produções e do trabalho realizado pelo grupo, a partir de um parâmetro baseado em qualidades técnicas da produção ${ }^{5}$.

5.

Para maiores detalhes, verificar Melo (2010).

Quadro 1. Respostas atribuídas pelos grupos que responderam ao questionário da pesquisa de Melo (2010) e respectivas justificativas. Acre, 2010.

\begin{tabular}{|c|c|c|}
\hline Grupos & Resposta & Justificativas Explicitadas \\
\hline G1 & Profissional & [...] o compromisso de qualidade estética nas criações artísticas. \\
\hline G2 & Profissional & Pela qualidade e compromisso com a arte. \\
\hline G3 & Profissional & $\begin{array}{l}\text { Acreditando no trabalho que se é feito de maneira profissional. Não é } \\
\text { um trabalho feito de qualquer maneira. }\end{array}$ \\
\hline G4 & Profissional & $\begin{array}{l}\text { [...] sabemos que somos definidos perante o mercado como "Amador", } \\
\text { mas temos práticas e talento de "Profissional". }\end{array}$ \\
\hline G5 & Profissional & $\begin{array}{l}\text { Porque sempre buscou primar pela qualidade técnica de seus atores. } \\
{[\ldots]}\end{array}$ \\
\hline G6 & Profissional & $\begin{array}{l}{[\ldots] \text { pela busca de novas técnicas, do descobrir da forma ideal da }} \\
\text { linguagem proposta pelo grupo. }\end{array}$ \\
\hline G7 & Profissional & $\begin{array}{l}\text { [...] Procuramos o estudo e pesquisa em todos os sentidos, nas áreas } \\
\text { acima citadas, a fim de qualificar e nos aprofundar naquilo que temos } \\
\text { como objetivo, o teatro. }\end{array}$ \\
\hline G8 & Profissional & [...] Busca pelas pesquisas (estudos) por novos caminhos estéticos. \\
\hline G9 & Profissional & Por termos como preocupação a encenação. \\
\hline G10 & Profissional & $\begin{array}{l}\text { [...] Acreditamos que todo grupo que se preocupa com a formação } \\
\text { continuada de seus integrantes e que vende seus espetáculos seja um } \\
\text { grupo profissional. [...] }\end{array}$ \\
\hline G11 & Profissional & $\begin{array}{l}\text { Pelo compromisso desenvolvido pelos atores mais antigos da companhia } \\
\text { [...] }\end{array}$ \\
\hline G12 & Profissional & $\begin{array}{l}\text { Dentro do grupo, digo, da companhia, os integrantes se envolvem em } \\
\text { todas as ações, seja como produtor, figurinista/aderecista, iluminador, } \\
\text { sonoplasta e ator/atriz[...] }\end{array}$ \\
\hline G13 & Profissional & $\begin{array}{l}\text { Apesar de não termos um grupo constituído juridicamente nos } \\
\text { consideramos profissionais. [...] Vale ressaltar que o diretor do grupo, } \\
\text { tem carteira profissional de ator e palhaço concebida pelo SATED-RJ. }\end{array}$ \\
\hline G14 & Amador & $\begin{array}{l}\text { Não vivemos da atividade, por conta de exercermos outras profissões e } \\
\text { pela inexistência de um mercado sólido. }\end{array}$ \\
\hline G15 & Amador & $\begin{array}{l}\text { Amamos o que fazemos. Estamos nos organizando internamente, } \\
\text { com um propósito de desenvolvermos um trabalho voltado para a } \\
\text { comunidade. Que já desenvolvemos a mais de } 6 \text { anos. }\end{array}$ \\
\hline G16 & Amador & Exatamente pela falta de estrutura que não temos. \\
\hline G17 & Amador & $\begin{array}{l}\text { Ainda faltam mais oficinas para o melhor desenvolvimento dos } \\
\text { membros da companhia. }\end{array}$ \\
\hline
\end{tabular}


Os grupos que se intitularam amadores, igualmente, o fizeram apontando carências, como não ter estrutura adequada (G16) ou a falta de oficinas para aprimoramento técnico dos atores (G17), aparecendo em apenas uma das respostas argumentos como os defendidos pela Confenata (G15).

A partir dessas respostas, é possível mapear algumas utilizações dos termos realizados por grupos de teatro no Acre no início do século XXI. Profissionais, para os participantes da pesquisa, são aqueles que possuem qualidade no trabalho realizado, registros em órgãos competentes, compromisso com o trabalho, estudos na área e técnicas desenvolvidas. Amadores, por outro lado, são os que ainda não puderam se desenvolver, os que não possuem estrutura, não desenvolveram técnica ou estudos. Enfim, amadores são os que ainda não conseguiram alcançar o status de profissional. Apenas na fala de um grupo pode ser percebido orgulho em se vincular ao termo amador. Para esse grupo, ser amador significa "amar o que se faz", com trabalhos voltados para a comunidade, nos mesmos parâmetros dos grupos afiliados à Confenata no século XX.

Percebe-se pelas respostas que a expressão amador ganha um sentido de teatro produzido por quem entende superficialmente de alguma coisa. É possível perceber isso em respostas como "[...] sabemos que somos definidos perante o mercado como amadores, mas temos práticas e talento de profissionais" (G4), e em falas como "ainda faltam mais oficinas para o melhor desenvolvimento dos membros da companhia" (G17). A primeira destas respostas, em particular, traz à tona a importância do reconhecimento do público para que uma companhia atinja, hoje, status de profissional, enquanto, no teatro produzido no início e em meados do século $\mathrm{XX}$, este reconhecimento por parte da sociedade (e a relação mercadológica que ele implica) não era tão valorizado pelos grupos de teatro amadores, bastando para esses artistas a vinculação a uma ideologia.

Carreira demostra que, nos últimos anos do século $\mathrm{XX}$, a noção de teatro de grupo no Brasil foi reprogramada pela introdução de elementos do marketing, com a aceitação da produção como um elemento importante para o teatro, e por uma preocupação técnica com as criações teatrais, em especial com o trabalho do ator (Carreira, 2008). Para este autor, companhias profissionais são, hoje, aquelas subsidiadas por recursos do governo ou de empresas que encontram nas leis de incentivo à cultura ou no marketing cultural um meio de ter tanto benefício financeiro (recursos para subsidiar e pagar os indivíduos) quanto uma imagem positiva perante a sociedade (valorização do trabalho realizado).

Conforme observamos nos estatutos e publicações das 
Confenatas, os grupos amadores do século XX orgulhavam-se de assim se intitular porque o uso deste termo lhes permitia, entre outros fatores, lutar pela democratização do acesso, não serem caracterizados como elencos flutuantes, exercer militância e desvincularem-se de relações comerciais que pudessem por em xeque a qualidade artística daquilo que produziam na condição de amadores. Esses elementos não necessariamente estão de acordo com as lógicas implantadas atualmente como práticas profissionais no teatro brasileiro, algumas delas apontadas por Carreira.

Um dos grupos entrevistados por Melo (2010) se definiu como amador e profissional, justificando sua escolha da seguinte forma: "Amador porque os integrantes não dependem financeiramente do teatro para viver. Profissional pela forma do trabalho, pela busca de novas técnicas, de descobrir a forma ideal da linguagem proposta pelo grupo". Percebe-se, neste caso, como os grupos que vivem de bilheterias esporádicas e, a maior parte do tempo, do investimento por parte dos próprios atores - tanto no que concerne ao tempo dedicado aos ensaios sem remuneração quanto, até mesmo, ao investimento financeiro na produção, pois dificilmente se faz teatro sem recursos materiais - são considerados amadores por esse grupo, embora também profissionais por darem conta de sua linguagem artística a partir de escolhas técnicas e/ou especializadas.

O amador e o profissional: uma vinculação ao mercado da arte

A partir dos dados levantados, o que se pode pensar sobre o amador e o profissional no teatro brasileiro do início do século XXI? Neste texto, atentamos para o fato de que, atualmente, outros sentidos são atribuídos para estes termos além da distinção relacionada ao fator financeiro. $O$ uso das palavras amador e profissional está ligado, hoje em dia, às questões de boa e má qualidade de produção, respondendo por parâmetros baseados na técnica para aspirar à legitimidade cultural - conceito cunhado por Bourdier (2007), que consiste no processo de validação de determinado segmento cultural para alcançar o seu valor no mercado cultural. Tal processo é regido por leis próprias a partir do capital simbólico de cada área, que irá determinar níveis de valores aos produtos culturais. Sobre legitimidade cultural, Bourdieu diz que

Se as relações constitutivas do campo de posições culturais não revelam completamente seu sentido e sua função a não ser quando referidas ao campo das relações entre as posições ocupadas por aqueles capazes de produzi-las, reproduzi-las e utilizá-las, tal 
ocorre porque as tomadas de posição intelectuais ou artísticas constituem, via de regra, estratégias inconscientes ou semiconscientes em meio a um jogo cujo alvo é a conquista da legitimidade cultural, ou melhor, do monopólio da produção, da reprodução, e da manipulação legítimas dos bens simbólicos e do poder correlativo da violência simbólica legítima (Bourdieu, 2007, p. 168).

Para Bourdier, desde o século XVI e XVII, as ciências e as artes estão amparadas pelo espírito capitalista e liberal, pregando a inovação e a autonomia. Para isso, desvincularam-se das coações religiosas e da aristocracia. A arte, que antes passava pela aprovação teológica ou pela cumplicidade dos cortesãos, precisou alcançar novos parâmetros para conseguir o seu amparo dentro do mundo capitalista, e passou, então, a ter seu valor amparado pela "legitimidade cultural". Canclini explica a relação entre campo cultural e capital simbólico em Bourdieu:

Para Bourdieu, cada campo cultural é essencialmente um espaço de luta pela apropriação do capital simbólico, e em função das posições que se tem em relação a esse capital - proprietários ou pretendentes - são organizadas as tendências - conservadoras ou heréticas. O lugar que o capital cultural ocupa em Bourdieu e a disputa por sua apropriação é desempenhado, em Becker, pelas convenções e pelos acordos que permitem que os antagonistas continuem seu trabalho: "As convenções representam o ajuste contínuo das partes que cooperam com relação às condições mutáveis em que elas atuam (Canclini, 1997, p. 41).

Entendendo o campo cultural como um lugar de antagonismos pela legitimidade cultural, é possível pensar a evolução dos termos amador e profissional no teatro brasileiro do final do século XX e início do século XXI. Desde a promulgação da Lei॰ 8.313, de 1991, que instituiu o Programa Nacional de Apoio à Cultura, cujo mecanismo baseia-se na dedução do Imposto de Renda a pagar, por pessoa física ou jurídica, modificou-se a noção de produção cultural no país. Essa lei começou, lentamente, a introduzir uma nova modalidade de recursos financeiros no setor artístico, mediante o mecanismo de incentivo fiscal. Os editais (dinheiro público) começaram a circular e a garantir um financiamento à cultura direto, por meio estatal. Firmaram a lógica de produção, descrita por Canclini:

Os empresários adquirem um papel mais decisivo que qualquer outro mediador esteticamente especializado (crítico, historiador da arte) e tomam decisões fundamentais sobre o que deve ou não deve ser produzido e transmitido; as posições desses intermediários privilegiados são adotadas dando maior peso ao benefício econômico e subordinando os valores estéticos ao que eles interpretam como tendências do mercado; a informação para tomar essas decisões é obtida cada vez menos por meios de relações personalizadas (como o do dono de galeria com seus clientes) e mais pelos procedimentos 
eletrônicos de pesquisa de mercado e contabilização do rating; a "estandardização" dos formatos e as mudanças permitidas são feitas de acordo com a dinâmica mercantil do sistema, com o que é manipulável ou rentável para esse sistema e não por escolhas independes dos artistas (Canclini, 1997, p. 63).

Nesse momento, segundo a lógica de legitimidade cultural, fez-se necessário criar-se uma elite que garanta o seu lugar dentro dessa nova forma de produção (não mais de venda direta, à mercê do gosto popular) e que, igualmente, sejam criados os antagonistas para os quais a produção teatral não se deve voltar, assumindo a função de "ilegítimos" do capital cultural teatral. No nosso entendimento, a noção de amador e profissional assumiu esta função.

O amador passou a significar arte popular, dos setores subalternos, ingênuos. Sua produção, quando muito, deve ser admirada longe dos circuitos oficiais. É taxada como produção "do estranho", "do esquisito", passível de ser admirada, mas sem valor capital. É dentro dos parâmetros profissionais, perfazendo a lógica da legitimidade - basilada, por sua vez, pelo capital cultural - que se deve criar a valorização ou o valor de mercado do teatro. E, embora o discurso da modernidade ainda esteja presente nos setores artísticos, buscando-se a afamada originalidade e autonomia, o capital simbólico do teatro brasileiro do final do século XX e início do século XXI está fora de expressões não oficiais - ou, em outras palavras, fora do que não é padrão (profissional).

Os profissionais das artes que detêm o conhecimento especializado, capazes de comercializar seu produto artístico com base nas leis precedidas pelos manuais de legitimidade teatral, são os legítimos detentores da possibilidade de produção; logo, é para quem os mercados de artes, as leis de incentivos e o marketing cultural devem se voltar. São os legitimados, os que detêm as condições de fazer e dizer. Os outros são os amadores, os ingênuos, populares, que merecem estar apenas em condição de observar e ser observados como exóticos, almejando, um dia, obter o conhecimento dos especialistas.

Enfim, o amador passou a ser o outro da relação, o antagônico, dentro de uma lógica de organização social liberal. Representa aquele que está para fora das leis da produção e da legitimidade; não pertence ao núcleo dos que detêm o capital cultural - ou seja, não deve ter participação na produção, e tampouco o mercado e a legitimidade da arte devem se voltar para ele, coforme o pensamento de Canclini, que afirma

Por isso, as práticas populares são definidas, e desvalorizadas, mesmo por esses setores subalternos, tendo como referência, o 
tempo todo, a estética dominante, a dos que saberiam de fato qual é a verdadeira arte, a que pode ser admirada de acordo com a liberdade e o desinteresse dos "gostos sublimes (Canclini, 1997, p. 42).

Essa disputa é acentuada pela lógica do "atorcentrismo", que se pode definir como o enfoque na atuação/interpretação como elemento central do fazer teatral. Isso significa que uma valorização excessiva do trabalho do ator como elemento primordial do teatro veio a definir, como essência da arte teatral, a preocupação com questões relacionadas às técnicas de atuação, como se quem dominasse tecnicamente o trabalho de ator fosse capaz de produzir com mais qualidade do que aqueles que se dedicam ao teatro por outros motivos, como tão somente "o amor pela arte" ou a militância e engajamento político dos amadores, demarcando o capital cultural da área de teatro no Brasil desse período.

Os grupos cuja prática é focada no trabalho do ator - que detém o conhecimento especializado - é que possuem a legitimidade, a partir da valorização deste capital cultural.

\footnotetext{
Algumas utopias da modernidade, que estiveram no fundamento dessas instituições - divulgar e democratizar as grandes criações culturais, valorizadas como propriedade comum da humanidade - passam a ser, no sentido mais maligno, peças de museus (Canclini, 1997, p. 61).
}

A prerrogativa ideológica não é mais algo vendável. Ou jogam-se as regras do mercado ou se está fadado ao fracasso. Não há espaço para lacunas, para prerrogativas, para crenças, como a dos amadores: a objetividade comercial e o conhecimento especializado devem prevalecer.

Concluímos, assim, que o problema do amador no teatro brasileiro da atualidade, reside, enfim, na sua desvinculação do sentido comercial. É importante registrar que poucos grupos, amadores ou profissionais, conseguem ter financiamento contínuo de suas produções. Por isso, é difícil separar as práticas de grupos umas das outras, na medida em que, se os integrantes precisam ter outras atividades de trabalho para prover o seu sustento - e, em alguns casos, para custear o próprio grupo de teatro - isso não significa, no entanto, que façam um teatro de qualidade inferior. Pelo contrário: se, por um lado, o exercício de outras profissões prejudica a dedicação exclusiva ao teatro, por outro lado permite a esses artistas que tenham uma postura mais ideológica do que meramente técnica e que, por conseguinte, sejam mais abertos a novas práticas experimentais - como almejavam os grupos vinculados à Confenata.

Muitas vezes, é no contexto dos agrupamentos amadores 
que a linguagem do teatro se modifica, como bem observa Canclini, tanto como meio da educação e trabalho social quanto como viabilizador de novas técnicas - abrindo possibilidades de mudanças nas estruturas poéticas vigentes e cumprindo, desta forma, seu papel como agente de transformação social e cultural de uma sociedade. O teatro praticado de forma amadora por razões ideológicas, no século $\mathrm{XX}$, proporcionou a seus integrantes um sentimento de pertencimento, e este é um elemento facilitador da entrega à prática teatral, podendo propiciar uma inovação técnica que, em um primeiro momento, pode permanecer peculiar ao grupo, mas que, em alguns casos, acaba por tornar-se vanguarda, contribuindo para a área de conhecimento teatral. Isto pode ser verificado em grupos da década de 1960 e 1970, como o Arena e o Oficina, ambos de São Paulo-SP. A resposta de Canclini para o problema da submissão da arte a parâmetros e dogmas pertencentes ao mercado é excelente: "falta criatividade" (1997, p. 64).

Enquanto a sociedade equiparar a noção de teatro profissional com a ideia de "teatro de qualidade", partindo de uma valoração meramente técnica de modelos estrangeiros e da lógica de legitimidade cultural, fica difícil, para os grupos que almejam dedicar-se ao teatro por outros mecanismos, quererem permanecer nesta condição - eles passam a querer ter o status de profissionais, em busca de um reconhecimento por parte do público, como pode ser observado nas falas de grupos de teatro do Acre pesquisados por Melo (2010). Isso, no entanto, não significa que esses agrupamentos serão os precursores de qualquer inovação - ao contrário, em muitos casos poderiam contribuir mais enquanto propulsores de novas linguagens teatrais na condição de excluídos do sistema.

À medida que o teatro, no modelo amador, prossegue com sua prática, ele está mais próximo do sentido pleno de teatro profissional do que muitos grupos profissionais que, confortáveis com a garantia do apoio financeiro, entregam-se às lógicas de mercado, deixando de rever seus próprios métodos, tanto no que diz respeito à técnica quanto à própria ideologia. A técnica precisa, necessariamente, ser constantemente revista, devidamente apropriada e adaptada, para contemplar sua função de servir como meio para que o artista crie a partir de seu contexto social, político e econômico.

Do ponto de vista do ator, a prática do teatro amador reflete-se em decisões cruciais que norteiam sua carreira. Há atores que não fazem o teatro com que sonham porque precisam se adequar às demandas do mercado. Há aqueles que, para fazer o teatro que desejam, concentram suas atividades profissionais em outras áreas de atuação (lecionar, produções culturais 
ou mesmo atividades não relacionadas à arte) e tocam sua prática teatral de forma amadora ao longo de toda a sua carreira.

Por tudo isso, entendemos que a desvalorização do termo amador, no Brasil, no que se refere ao teatro do início do século XXI, caminha junto a uma séria decadência no alcance e na prática teatral, tendo o mercado de arte prevalecido como a tendência predominante do fazer teatral. Por isso, recai sobre qualquer tentativa inovadora uma conotação negativa com que é, em geral, avaliada. O que precisa ser revisto é a concepção de arte vigente em nossa sociedade, que ainda tem arraigada em seu modo de pensar ideias utilitaristas a respeito da arte, as quais sufocam possibilidades diferentes daquelas culturalmente legitimadas. 


\section{REFERÊNCIAS}

BERNSTEIN, Ana. A Crítica cúmplice: Décio de Almeida Prado e a formação do teatro brasileiro moderno. São Paulo: Editora IMS, 2005, p. 44.

BOURDIEU, Pierre. A economia das trocas simbólicas. São Paulo: Perspectiva, 2007.

CANCLINI, Nestor Garcia. Culturas híbridas: estratégias para entrar e sair da modernidade. São Paulo: Editora da Universidade de São Paulo, 1997.

CARREIRA, André. Teatro de grupo: a busca de identidades. Subtexto: Revista de Teatro do Galpão Cine Horto (Belo Horizonte), 1(5): 11-20, dezembro 2008.

ENCICLOPÉDIA ITAÚ CULTURAL. Os Comediantes. Disponível em: http://www.itaucultural.org.br/aplice

xternas/enciclopedia_teatro/index.cfm?fuseaction=cias_biografia\&cd_verbete $=641 \& l s t$ _palavras $=\& c d$ _idioma $=28555$ Acesso em: 21 mar 2011

FARIA, João Roberto; GUINSBURG, Jacob; LIMA, Mariângela Alves de. Dicionário do Teatro Brasileiro. 2.ed. São Paulo: Perspectiva, 2006.

KÜHNER, Maria Helena. Teatro Amador: Radiografia de uma Realidade (1974 - 1986). Rio de Janeiro: INACEN, 1987.

MELO, Elderson. Teatro de grupo no Estado do Acre: trajetória, prática e a inserção do estilo regional. Dissertação de Mestrado em Artes. Universidade Estadual de Campinas, Instituto de Artes, 2010.

PALOTTINI, Renata. Amor ao amador. Argumento, s. l, v. $1, n$. 3, pp. 75-80, jan. 1974.

VARGAS, Maria Thereza; MAGALDI, Sabato. Cem anos de teatro em São Paulo. São Paulo: Editora Senac São Paulo, 2000. 